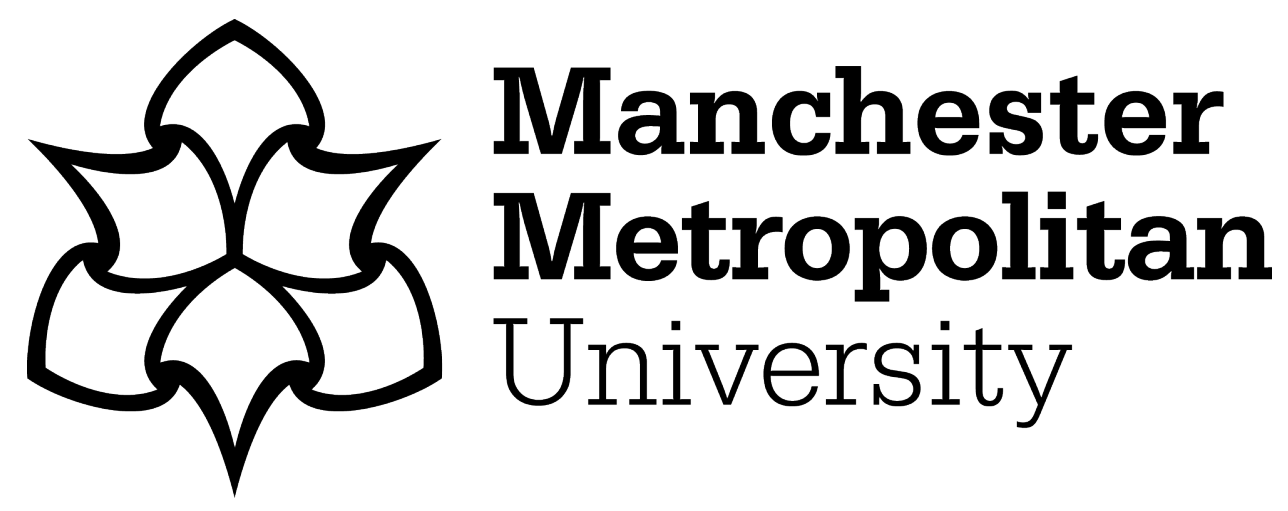

Dao, Phung ORCID logoORCID: https://orcid.org/0000-0002-8612-5589, Nguyen, Mai ORCID logoORCID: https://orcid.org/0000-0003-1276-8589 and Chi, Do-Na (2021) Reflective learning practice for promoting adolescent EFL learners' attention to form. Innovation in Language Learning and Teaching, 15 (3). pp. 247-262. ISSN 1750-1229

Downloaded from: https: //e-space.mmu.ac.uk/625742/

Version: Accepted Version

Publisher: Taylor \& Francis

DOI: https://doi.org/10.1080/17501229.2020.1766467

Please cite the published version 
adolescent EFL learners' attention to form. Innovation in Language Learning and Teaching. DOI: $10.1080 / 17501229.2020 .1766467$

\section{Reflective learning practice for promoting adolescent EFL learners' attention to form}

Abstract

To address learners' low attention to form in peer interaction, the current study investigated the impact of reflective learning practice intervention that aims to promote learners' attention to form. Sixty-eight adolescent EFL learners $\left(M_{\mathrm{age}}=15.6, S D=7.05\right)$ formed reflective learning practice and control groups. The reflective practice group received a treatment that was designed following the reflective learning model (Kolb, 2014) with the goal of increasing learners' attention to form. Pre/post-tests results showed that learners' attention to form in the type of self-correction and metalinguistic talk increased over time. Self-reports revealed that learners perceived the reflective learning practice as beneficial, particularly encouraging them to attend to language form and establish collaborative mindset. However, factors such as learners' approach to tasks, social relationship, perceptions of feedback provision, and proficiency appeared to mediate the effectiveness of the treatment. The results suggest reflective learning practice as a pedagogical tool to promote effective peer interaction.

Key words: Reflective learning practice; attention to form; LREs; peer interaction, pedagogical intervention

\section{To cite this article:}

Dao, P., Nguyen, M. NXC, Chi, D. (2020, in press). Reflective learning practice for promoting adolescent EFL learners' attention to form. Innovation in Language Learning and Teaching. Published online in 2020. DOI: 10.1080/17501229.2020.1766467 
Dao, P., Nguyen, M. NXC, Chi, D. (2020, in press). Reflective learning practice for promoting

adolescent EFL learners' attention to form. Innovation in Language Learning and Teaching. DOI: $10.1080 / 17501229.2020 .1766467$ 
adolescent EFL learners' attention to form. Innovation in Language Learning and Teaching. DOI: $10.1080 / 17501229.2020 .1766467$

\section{Introduction}

Learner-learner interaction (henceforth peer interaction) is a cognitive and dynamic phenomenon with its inherently social nature (Sato, 2017a). It is perceived as a context where language use and language learning take place (Philp, Adams \& Iwashita, 2014; Sato \& Ballinger, 2016). On the one hand, previous research has suggested that peer interaction provides learners with opportunities to attend to language form through interactional feedback, discussion of language features, and collaborative learning (Fujii, Ziegler, \& Mackey, 2016). On the other hand, the benefits of peer interaction to L2 learning are susceptible to a variety of contextual and social factors such as learners' pair/group dynamics (Storch, 2002), collaborative mindset-a disposition toward the need of being collaborative in interaction (Sato, 2017b), learners' perceptions of their peers and approach to tasks, interaction mode, task type, and proficiency (see Sato \& Ballinger, 2016).

Despite its potential for creating a facilitative context for L2 development, one of the major shortcomings of peer interaction is that learners' attention to form and negotiation for meaning, considered central to L2 learning, are relatively low during peer interaction (Philp, Walter \& Basturkmen, 2010). To address this limitation, few studies have carried out pedagogical interventions to promote learners' attention to form. They included modelling a collaborative interaction (Kim \& McDonough, 2011), training the learners on providing peer feedback (Sato \& Lyster, 2012), teaching interactional strategies (Fujii et al., 2016), offering interaction strategy instruction (Author, XXXX), providing metacognitive instruction on language rules, corrective feedback and collaborative interaction (Sato, 2020; Sato \& Loewen, 2018), and using multiple-stage pedagogical interventions to focus learners' attention on form (Brooks \& Swain, 2009)

Despite providing some evidence for positive impact of the pedagogical interventions on different features of interaction, these studies revealed some limitations. First, they have rarely based the design of the interventions on a specific theoretical framework. Additionally, the interventions were mostly conducted on adult university learners following a teacher-centered 
approach, with the teachers/researchers explicitly explaining the instruction (e.g. modelling or explaining the interactional strategies) and the learners practising them subsequently. Furthermore, the studies did not take into consideration learners' perceptions of factors that might mediate the impact of the interventions. To address these issues, the current study carried out a learner-centered pedagogical intervention, so-called reflective learning practice that is based on the reflective learning model (Kolb, 1984, 2014; Schon, 2016) to promote adolescent learners' attention to form during peer interaction. The study also explored learners' perceptions of contextual and social factors that mediate the effectiveness of the intervention.

\section{Learners' attention to form}

Previous research has suggested that although much interaction was observed among learners during task completion, learners' attention to form during peer interaction remained relatively low, especially when the interaction was meaning-focused (Philp et al., 2010). Promoting learners' attention to form has been emphasized due to its important role in facilitating L2 development. Learners' attention to form that emerges incidentally during peer interaction is believed to enable learners to "understand the relationship between the meaning, forms, and functions in a highly context-situation" (Swain, 1998, p.69), and thus promote language production accuracy. An example of learners' incidental attention to form can be seen in Language-Related Episodes (LREs), a talk segment in which "learners talk about the language they are producing, question their language use, correct themselves or others" (Swain \& Lapkin, 1998, p. 104).

To date, three major proposals have been put forward to suggest ways of promoting learners' attention to form. The first proposal is to design tasks in a way that learners' attention could be drawn to form during interaction. One example of this proposal is to use focused tasks, a type of tasks in which learners would have to use specific language features during interaction to complete the tasks (Authors, XXXX). The second proposal is to manipulate implementation condition, which could be classified into two broad instructional approaches. The first approach is 
conducted to the discretion of teachers, meaning that the teachers intentionally draw learners' attention to form during task implementation irrespective of task design (Samuda, 2001). The second approach is to set up an interaction condition that could promote learners' attention to form. It includes task repetition, e.g., repeating a task multiple times (Kim \& Tracy-Ventura, 2013), pretask planning (Pang \& Skehan, 2014), and manipulating post-task conditions and public performance (Skehan, 2016).

Research findings on the effectiveness of the aforementioned proposals have shown that manipulating task design and task implementation had positive impacts on learners' attention to form and task performance in terms of complexity, accuracy, and fluency. However, a variety of variables mediating the effectiveness of the manipulation of task design and implementation condition were also reported, including learners' approach to tasks, proficiency, and social relationship (Authors, XXXX; Philp \& Mackey, 2010). This suggests that these factors need to be taken into consideration when introducing interventions that aim to promote learners' attention to form in peer interaction. Additionally, research has recently suggested another proposal, which involves giving explicit instructions prior to interaction to increase learners' attention to form. The next section will describe these pedagogical interventions.

\section{Promoting learners' attention to form through pedagogical interventions}

To increase learners' attention to form, recent studies have conducted different pedagogical interventions. One of these interventions is pre-task modelling (Kim \& McDonough, 2011).

Specifically, prior to their interaction, the learners were modelled on how to interact

collaboratively. Findings showed that pre-task modelling resulted in greater amount of discussion of form (i.e. LREs), more accurate resolution of language problems, and more frequent collaborative dynamics. Another intervention for promoting learners' attention to form is to provide metacognitive instruction on how to become an active learner through raising awareness about the benefits of communicative interaction, and using different interactional moves (e.g. clarification 
requests, recasts, confirmation checks) (Fujii et al. 2016). The results indicated positive impacts of the metacognitive instruction due to learners' more frequent provision and use of interactional moves (i.e. feedback) and greater awareness of the importance of using interactional moves for L2 learning.

Sato and Lyster (2012) focused exclusively on 'teaching learners to provide corrective feedback' to enhance their attention to form. Following a three-stage-procedure, learners were first presented with corrective feedback techniques in the preparation stage, then applied them in the practice phase. In the expansion stage, they were encouraged to use corrective feedback during interaction. Results indicated that the teaching of corrective feedback technique significantly affected the frequency of interactional moves, including corrective feedback and modified output. Further analyses showed that frequency of feedback produced in the group that received the treatment was significantly correlated with development of accuracy and fluency (i.e. pruned speech rates). In a related study, Sato (2013) found that teaching corrective feedback helped increase trust among learners. Furthermore, the teaching of corrective feedback in combination with explicit explanation of language rules was reported to enhance the effectiveness of feedback, particularly recast, on language development (Sato \& Loewen, 2018). In addition to teaching students to provide corrective feedback, Sato and Ballinger (2012) included the teaching of peer language learning strategies such as seeking and providing language help, interacting collaboratively in the target language, and recognising and making use of learning opportunities in interaction. They found that this explicit instruction enhanced learners' language awareness; however, learners' collaborative mindset was suggested to shape the learners' interaction behaviour and mediate the effectiveness of the training, which then affected their interaction dynamics and the subsequent learning outcome. In addition, using a multi-stage metacognitive instruction for promoting collaborative interaction, Sato (2020) found that this pedagogical support increased learners' interaction strategy use and improved their L2 comprehensibility. 
adolescent EFL learners' attention to form. Innovation in Language Learning and Teaching. DOI: $10.1080 / 17501229.2020 .1766467$

These studies collectively evidenced that pedagogical interventions had positive impacts on learners' attention to form. However, it appears that many of these interventions were conducted in a relatively teacher-fronted fashion and were not based explicitly on a specific theoretical model. Additionally, the training techniques in these interventions was predetermined by the researchers without taking learners' perspectives into consideration. Thus, a pedagogical intervention drawing explicitly on a specific theoretical basis, promoting learner-centered approach, and taking learners' prior experience into account, may potentially have greater positive impacts on learners' interaction, specifically their attention to form. Given these considerations, this study proposed reflective learning practice as a theoretically supported and learner-centered intervention that has potential in promoting learners' attention to form during interaction. The following section describes reflective learning practice and its potential in promoting learner attention to form

\section{Reflective learning practice}

In higher education, reflective learning practice refers to a cognitive process that involves consciously thinking about and continuously analysing one's past experiences (Kolb, 1984; Schon, 2016). From the common-sense view, reflective learning practice is simply akin to thinking or a form of metal processing, which is performed to serve a purpose or achieve an outcome (Moon, 2015). However, from the academic perspective, reflective learning practice is extended to refer to not just a form of thinking but a mental effort that occurs in a specific context, follows a specific structure, and is affected by different contextual factors (Hinnett, 2003). In other words, reflective learning practice needs to be carried out with a specific goal and purposely structured in order to achieve certain learning outcomes. In addition, reflective learning practice exhibits characteristics of self-regulated learning in which learners regulate and control their cognition (Pintrich, 2000) and/or plan, monitor and evaluate their own learning (Wenden, 1987). This self-regulating characteristic, which reflects learner-centered learning, has been shown to be beneficial to L2 learning when it is applied in L2 research (see Sato, 2020; Teng \& Zhang, 2016). 
Reflective learning practice is believed to assist learners in engaging deeply with the learning process and therefore enables them to improve future performances through constant analysis of past performances (Kolb, 1984, 2014). According to the reflective and experiential learning model, reflective practice represents a learning cycle, in which learners (a) do the activities (i.e. concrete experience), then (b) observe and reflect on this experience in order to (c) form abstract concepts and generalization before (d) testing and applying these concepts in new contexts, which then serves as a new concrete experience (i.e. the initial stage of the cycle).

Reflective learning practice has been shown to be effective in promoting learning in diverse educational contexts and varied disciplines (see Barkhuizen, 2010; Farrell, 2011). One of the roles of reflective practice in fostering learning is that it transforms experiential and tacit knowledge into principled explicit knowledge, links existing knowledge to analysing the relationship among past experience, current performance and future actions, and fosters the re-organisation of knowledge in order to gain further insights and achieve both anticipated and unexpected learning outcomes. Applied into L2 learning in the context of peer interaction, reflecting on previous experience in interaction would raise learners' awareness through analysing their interactional behaviour and language use/production, which potentially encourages them to adjust their interaction behaviours and promote greater attention to language form. Reflective learning has been used widely in language teacher training programs (Barkhuizen, 2010; Farrell, 2011). However, little research to date has reported whether this reflective learning practice could be one of the potentially effective pedagogical procedures that promotes learners' attention to form during peer interaction. Theoretically, because the reflective learning practice encourages learners to reflect continuously on their past interaction experience, language production, and language use, it is proposed that this successively conscious reflection could enhance the collaborative pair/group dynamics and ultimately promote learners' attention to form.

\section{The current study}


This study examined whether reflective learning practice designed following the reflective learning cycle model (Kolb, 1984, 2014; Schon, 2016) promoted learners' attention to form during peer interaction. Instead of using adult university learners, this study recruited young learner participants (i.e. $7^{\text {th }}$ and $8^{\text {th }}$ graders) with the goal of providing more generalizable results to different populations of L2 learners. The study also explored the learners' perceptions and identified contextual and social factors that mediate the effectiveness of the intervention.

\section{Research questions}

1. Does the reflective learning practice affect learner attention to form in peer interaction?

2. What are learners' perceptions of the impact of reflective learning practice on their interactional behaviors?

3. What are factors mediating the impact of reflective learning practice?

\section{Method}

\section{Participants}

Participants were 68 adolescent Vietnamese EFL learners (36 females) whose age ranged from 11 to 16 years old $(M=15.6, S D=7.05)$. They were $7^{\text {th }}$ and $8^{\text {th }}$ graders at 13 secondary schools in a city in Vietnam but were all enrolled in an 18-month English program at a private center. Their English proficiency assessed by a TOEIC test was $438.48(S D=151.36)$. They reported to have learnt English for a mean of 7.67 years $(S D=2.66)$. They were randomly divided into reflective practice and control groups. Because some participants failed to complete all research activities, the number of participants in two groups was uneven, with 20 dyads in the reflective practice group and 14 dyads in the control group. The reflective practice group had an average TOEIC score of 471.15 $(S D=108.28)$ whereas the control group's mean TOEIC score was $476.79(S D=178.94)$.

\section{Design}

The study used a pre/post-test design to investigate the impact of reflective learning practice on learners' attention to form. Dependant variable was learner attention to form operationalised as 
language-related episodes (LREs) that indicate learners' explicit discussion of form, self-correction and other-correction. Independent variable was reflective learning practice with two levels: presence and absence of reflective learning practice activities. The reflective practice group received the treatment (i.e. carrying out reflective practice activities in two sessions in two consecutive weeks), whereas the control group only carried out the same pre/post-test tasks and interactive tasks.

The reflective learning practice was designed following the reflective learning model (Kolb, 2014; Schon, 2016) that conceptualizes reflective learning practice as a cyclical process, consisting of four stages: (a) Concrete experience $\rightarrow$ (b) Reflective observation $\rightarrow$ (c) Abstract conceptualisation $\rightarrow$ (d) Active experimentation. Table 1 describes the study design.

Table 1

Study design

\begin{tabular}{|c|c|c|c|}
\hline Week & & Reflective practice group & Control group \\
\hline \multicolumn{2}{|l|}{1} & \multicolumn{2}{|c|}{ Project introduction, consent, and background questionnaire } \\
\hline \multirow{14}{*}{2} & \multirow{2}{*}{$\begin{array}{l}\text { Pre- } \\
\text { tests }\end{array}$} & Picture-sequencing task & Picture-sequencing task \\
\hline & & Problem-solving task & Problem-solving task \\
\hline & \multirow{12}{*}{ 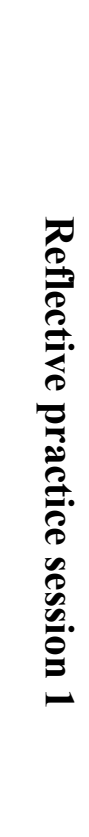 } & Stage 1. Concrete experience-Doing & \\
\hline & & interactive tasks (pre-tests above) & \\
\hline & & Stage 2. Reflective observation -Reflecting & Do not do reflective \\
\hline & & on the experience of executing pre- & practice activities \\
\hline & & test tasks & \\
\hline & & Stage 3. Abstract conceptualisation - & \\
\hline & & Learning from the experience of & \\
\hline & & executing tasks) & \\
\hline & & Stage 4. Active experimentation-Trying out & Carry out communicative \\
\hline & & new communicative tasks: & tasks (Stage 4): \\
\hline & & - Narrative, Debate and Discussion task & Narrative, Debate and \\
\hline & & & Discussion task \\
\hline
\end{tabular}

Exit questionnaire 


\begin{tabular}{|c|c|c|c|}
\hline \multirow{6}{*}{3} & \multirow{6}{*}{ 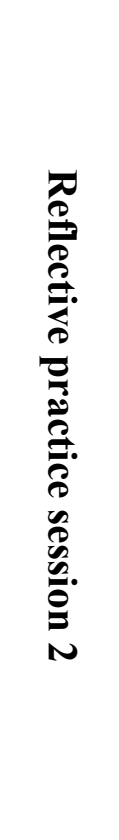 } & $\begin{array}{l}\text { Stage 1. Concrete experience-Doing tasks } \\
\text { (from Stage 4) }\end{array}$ & \\
\hline & & $\begin{array}{c}\text { Stage 2/ } 3 \text {. Reflective observation \& abstract } \\
\text { conceptualisation (combined) }\end{array}$ & $\begin{array}{l}\text { Do not do reflective } \\
\text { practice activities }\end{array}$ \\
\hline & & $\begin{array}{l}\text {-Reflecting on the experience of } \\
\text { executing three tasks } \\
\text {-Learning from the experience of } \\
\text { executing the three tasks) }\end{array}$ & \\
\hline & & $\begin{array}{c}\text { Stage 4. Active experimentation -Trying out } \\
\text { new communicative tasks: }\end{array}$ & $\begin{array}{l}\text { Carry out communicative } \\
\text { tasks: }\end{array}$ \\
\hline & & - Narrative, Debate, Discussion task & -Narrative, Debate, \\
\hline & & Exit questionnaire & Discussion task \\
\hline \multirow{2}{*}{4} & Post- & Picture-sequencing task & Picture-sequencing task \\
\hline & tests & Problem-solving task & Problem-solving task \\
\hline
\end{tabular}

In Table 1, the reflective practice group received two reflective learning practice sessions in two weekly learning sessions in the second and third week of learning. In Stage 1 (concrete experience) the learners were randomly paired and did a picture-sequencing task and a problem-solving task that served as pre-tests. In Stage 2 (reflective observation), they individually carried out a reflective observation activity by writing answers on a piece of paper to the questions that guided them to reflect on their experience of doing the pre-test tasks. The questions concerned (a) the extent to which they attend to language issues, (b) communication strategies (e.g. what they should do when encountering language and communication issues or when a partner asks for help, (c) amount of language production, (d) difficulties during interaction, and (e) their feelings in interaction. Answers for these questions were then used for Stage 3.

Stage 3 (i.e. abstract conceptualisation or learning from the experience) consisted of learners' discussion and an awareness-raising session. In learners' discussion, they compared in small groups their answers from Stage 2 to identify similarities and differences in terms of their 
interactional behaviour and interaction difficulties. Based on this reflection, they discussed characteristics of an effective interlocutor. To stimulate the discussion, they received prompt questions such as 'what should you do (a) when you/your partner are speaking/listening, (b) when language errors occur, (c) when your partner asks for help, and (d) how to collaborate well with partners?'. At the end of the discussion, they reported orally their discussion to the whole class regarding characteristics of an effective interlocutor, how to address difficulties during interaction, and communication strategies.

In the learners' awareness-raising session, the teacher made a brief ten-minute presentation to the whole class about the benefits of meaning-focused peer interaction, characteristics of a collaborative interaction, shortcomings of peer interaction (e.g. lack of attention to form), and summed up a list of communication strategies suggested by the learners. To help the learners set a collaborative mindset prior to interaction, promote collaborative pair dynamics, and elicit more communications strategies, the teacher provided two excerpts of peer interactions and asked the learners to judge which interactions showed learners' collaborative dynamics and greater attention to language issues, and also identify communication strategies. At the end of this session, the teacher stressed the importance of maintaining a collaborative mindset and carrying out the interaction collaboratively through (a) idea-sharing, (b) asking and answering questions, (c) providing feedback, and (d) effort in resolving linguistic problems. Following the reflective and abstract conceptualization stage, the learners were encouraged to apply what had been learnt into carrying out three tasks that served as active experimentation (Stage 4). In the following week, the learners carried out another similar reflective practice session, with reflective observation and abstract conceptualisation (Stage 2 and 3) being combined due to the class time limitation. They completed post-tests in pairs in the subsequent week. 
Different from the reflective practice group, the control group did not do reflective practice activities (Stages 2 and 3) but carried out all other activities: the same pre/post-test tasks (Stage 1), and communicative tasks (Stage 4) to control for practice effect.

\section{Tasks and materials}

The study used five types of communicative tasks: picture-sequencing, problem-solving, narrative, debate, and discussion tasks. For the picture-sequencing task, learners arranged ten pictures to create a story, whereas in the problem-solving task, they discussed to identify problems of the Vietnamese society and proposed solutions. Two similar versions of picture-sequencing and problem-solving tasks were used as pre/post-test tasks. To control for the potential impact of task topic, pictures used for pre/post-test tasks depicted a similar topic (i.e. accidents). Topics of the problem-solving task concerned two social problems that the students were familiar with (teenager and family problems). The narratives were story-retells based on a video or personal experience. Debate tasks asked learners to defend their decisions in two scenarios, and discussion tasks required them to discuss a plan for a birthday party or a family vacation.

The materials also included an exit-questionnaire, consisting of five open-ended questions investigating learners' perceptions of the reflective learning practice such as usefulness, application, difficulties of the learnt techniques and suggestions for improving the training. The semi-structured interview questions included clarification of learners' responses in the questionnaire that focused on identifying contextual and social factors that mediate the impact of the intervention. The exitquestionnaire and interviews were conducted in Vietnamese.

\section{Procedure}

Data collection took place over a five-week period. In week 1, the learners and their parents completed a consent form and a background questionnaire. In week 2 , the reflective practice group carried out pre-test tasks in randomly assigned dyads within twenty-five minutes (Stage 1), followed by a forty-minute reflective learning session (Stages 2 and 3) and forty-minute active 
experimentation (Stage 4). They also completed an exit-questionnaire within fifteen minutes. After Stage 3, they had a 15-mintue break to avoid fatigue. The control group carried out the same pretest tasks and three communicative tasks (the same tasks performed by the treatment group in Stage 4), but they did not receive a reflective practice session. In week 3, the reflective practice group continued carrying out reflective practice activities (30 mins) and three communicative tasks in the active experimentation stage (40 mins) and completed an exit-questionnaire (15 mins). The control group performed the same three communication tasks as the reflective group did in the active experimentation stage. In week 4, both groups did the post-tests in pairs (picture-sequencing and problem-solving tasks). In week 5, eight 30-minute semi-structured interviews (five learners per interview) were conducted. Digital audio-recorders (one per pair) were used to record learners' interactions in pre/post-tests.

\section{Analysis}

Audio-recorded interactions of pre/post-test tasks were transcribed by research assistants and verified by the first researcher. The interactions were coded for learner attention to form operationalised following Swain and Lapkin's (1998) definition of LREs as talk segment where learners correct their own errors (self-correction), correct partner's errors (other-correction), and discuss explicitly language use and/or seek language assistance (metalinguistic talk). Excerpt 1, taken from a discussion task about family problems, demonstrates learners' self-corrections.

\section{Excerpt 1. LREs (Self-correction)}

1 P1: yeah so I think some husbands and some wives is are very selfish so they doesn't they doesn't they don't give money to each other

\section{P2: Uh}

In Excerpt 1, the learner P1 self-corrected her errors twice. The self-corrections concerned the errors of subject and verb agreement such as wives is are, and they doesn't they doesn't they don't. Excerpt 2, taken from vacation accident task, illustrates a learner's other-correction. 


\section{P1: They swimming}

2 P2: They swam quá khứ [past tense]

3 P1: Uh and we they play...

In Excerpt 2, the learner P2 corrected his partner's errors of tense use from they swimming to they swam and explicitly stressed his correction 'quá khú [past tense]'.

Excerpt 3, taken from home accident task, shows an occasion where learners were talking explicitly about language use.

Expert 3. LRE (Metalinguistic talk)

1 P1: She was jogging

2 P2: Quá khứ hả? [Use past tense?]

3 P1 Uhm vì mình đang kể lại ...[Yes because we are re-telling....]

4 P2 She go shopping okay...vậy nguyên cái khúc này mình kể quá khư hay sao? [so for this whole part do we use simple past tense to re-tell?]

5 P1 Hiện tại cũng được... nhưng mà mình kể lại nên dùng quá khứ là tốt hơn...hiểu chưa? [Simple present tense is possible...but we are retelling so it is better to use simple past tense...understand?]

$6 \quad$ P2 Okay...

In Excerpt 3, when learner P1 used simple past tense to describe a picture (line 1), learner P2 checked whether simple past tense was appropriate (line 2). The learner P1 confirmed that the use of past tense was correct 'yes' (line 3) and stated a reason 'because we are re-telling' (line 3). However, the learner P2 continued using simple present tense 'she go shopping okay' (line 4) but later paused and checked whether the whole story should be retold using past tense (line 4). The learner P1 responded 'Hiện tại cũng được' [simple present tense is possible], but later suggested using simple past tense (line 5), with which the learner P2 agreed. 
A second coder independently coded $25 \%$ of the data for LREs. Pearson correlation $r$ for frequency of LREs was .95 and Cohen's kappa $k$ for types of LREs (self-correction, othercorrection and metalinguistic talk) was $.92, .89$ and .93 , respectively. To examine whether the reflective learning practice affected learner attention to form, instances of self-correction, othercorrection and metalinguistic talk were summed per interaction. To control for speech quantity differences, a proportion score per interaction was computed by dividing the sum of all identified LREs by total words. Proportion scores (normalised scores) of pre/post-tests between the reflective practice and control groups were compared using non-parametric tests due to normality violations. Learners' responses from the exit-questionnaire and interviews were qualitatively analysed by identifying common themes to investigate learners' perceptions of the impact of the reflective learning practice, and factors mediating this impact.

\section{Results}

\section{Impact of the reflective learning practice}

To examine whether reflective learning practice affected learners' attention to form, LREs in interactions from pre/post-tests were identified. Descriptive statistics for pre/post-test scores are presented in Tables 2 and 3.

Table 2

Means and standard deviations for pre/post-test scores (picture-sequencing task)

\begin{tabular}{|c|c|c|c|c|c|c|c|c|c|c|c|c|c|c|c|c|}
\hline & \multicolumn{8}{|c|}{ Reflective practice group (20 dyads) } & \multicolumn{8}{|c|}{ Control group (14 dyads) } \\
\hline & \multicolumn{4}{|c|}{ Pre-test } & \multicolumn{4}{|c|}{ Post-test } & \multicolumn{4}{|c|}{ Pre-test } & \multicolumn{4}{|c|}{ Post-test } \\
\hline & \multicolumn{2}{|c|}{ Raw } & \multicolumn{2}{|c|}{ By words } & \multicolumn{2}{|c|}{ Raw } & \multicolumn{2}{|c|}{ By words } & \multicolumn{2}{|c|}{ Raw } & \multicolumn{2}{|c|}{ By words } & \multicolumn{2}{|c|}{ Raw } & \multicolumn{2}{|c|}{ By words } \\
\hline & $\mathrm{M}$ & SD & $\mathrm{M}$ & SD & M & $\mathrm{SD}$ & M & $\mathrm{SD}$ & $\mathrm{M}$ & $\mathrm{SD}$ & M & SD & M & SD & M & SD \\
\hline Sum & 4.75 & .020 & .019 & .040 & 9.35 & 2.89 & .036 & .015 & 4.64 & 2.13 & .012 & .006 & 1.86 & 1.02 & .004 & .004 \\
\hline Self-correct & 2.35 & 1.87 & .009 & .020 & 3.85 & 1.57 & .012 & .007 & 3.07 & .99 & .009 & .003 & .57 & .76 & .001 & .002 \\
\hline Other-correct & 1.15 & 1.14 & .005 & .010 & .90 & .91 & .003 & .003 & 1.14 & 1.23 & .002 & .001 & 1.14 & .66 & .002 & .003 \\
\hline
\end{tabular}


$\begin{array}{lllllllllllllllll}\text { Metalinguistic } & 1.25 & 1.77 & .005 & .010 & 4.60 & 1.88 & .020 & .009 & .42 & .85 & .001 & .001 & .14 & .36 & .001 & .001\end{array}$ talk

Table 3

Means and standard deviations for pre/post-test scores (problem-solving task)

\begin{tabular}{|c|c|c|c|c|c|c|c|c|c|c|c|c|c|c|c|c|}
\hline & \multicolumn{8}{|c|}{ Reflective practice group (20 dyads) } & \multicolumn{8}{|c|}{ Control group (14 dyads) } \\
\hline & \multicolumn{4}{|c|}{ Pre-test } & \multicolumn{4}{|c|}{ Post-test } & \multicolumn{4}{|c|}{ Pre-test } & \multicolumn{4}{|c|}{ Post-test } \\
\hline & \multicolumn{2}{|c|}{ Raw } & \multicolumn{2}{|c|}{ By words } & \multicolumn{2}{|c|}{ Raw } & \multicolumn{2}{|c|}{ By words } & \multicolumn{2}{|c|}{ Raw } & \multicolumn{2}{|c|}{ By words } & \multicolumn{2}{|c|}{ Raw } & \multicolumn{2}{|c|}{ By words } \\
\hline & M & SD & M & SD & M & SD & M & SD & M & SD & M & SD & M & SD & M & SD \\
\hline Sum & 4.60 & 4.07 & .007 & .003 & 5.70 & 3.37 & .011 & .004 & 3.00 & 2.04 & .008 & .006 & 1.64 & 2.13 & .0025 & .003 \\
\hline Self-correct & 2.45 & 2.06 & .004 & .003 & 3.25 & 1.37 & .007 & .004 & 1.71 & 1.90 & .005 & . 006 & .79 & 1.56 & .0013 & .002 \\
\hline Other-correct & .60 & 1.10 & .001 & .001 & .55 & 1.09 & .001 & .001 & .50 & .65 & .002 & . 003 & .36 & 1.08 & .0002 & .001 \\
\hline Metalinguistic & 1.55 & 2.19 & .002 & .002 & 1.90 & 2.22 & .003 & .003 & .79 & .97 & .002 & .002 & .05 & .75 & .0009 & .001 \\
\hline
\end{tabular}

Results of Mann-Whitney $U$-tests revealed that the reflective practice and control groups did not show significance differences in the amount (sum) of LREs on the pre-tests for both picturesequencing task, $U=.140, p=.89, \eta^{2}=.0006$, and problem-solving task, $U=.035, p=.98, \eta^{2}=$ .0001 , indicating that they were comparable before the treatment. Following the reflective practice intervention, the reflective practice group had significantly higher scores (sum) than the control group on the post-tests for both picture-sequencing task, $U=4.90, p=.0001, \eta^{2}=.73$, and problem-solving task, $U=4.31, p=.0001, \eta^{2}=.56$.

To gain more insight into which types of learner attention to form increased over time, scores for pre/post-tests of the reflective practice group were compared across types of LREs. For the picture-sequencing task, results of Wilcoxon Signed Ranks tests showed that learners' selfcorrection and metalinguistic talk increased significantly from pre- to post-tests, $Z=3.06, p=.002$, $\eta^{2}=.28$, and $Z=3.17, p=.002, \eta^{2}=.30$, respectively, but there were no significant increases in 
other-correction, $Z=.213, p=.202, \eta^{2}=.001$. For the problem-solving task, only learners' selfcorrection increased significantly over time, $Z=2.696, p=.007, \eta^{2}=.22$. The amount of othercorrection and metalinguistic talk did not increase significantly, $Z=.561, p=.58, \eta^{2}=.01, Z=$ $1.36, p=.17, \eta^{2}=.05$, respectively. In sum, the results indicated that the reflective practice increased learners' self-correction and metalinguistic talk, but it did not affect other-correction.

\section{Learners' perceptions of reflective learning practice}

The analyses of questionnaire and interview responses revealed learners' positive perceptions about the impact of reflective practice on different aspects of peer interaction. First, they reported higher attention to partners' language production as a result of the reflective practice. One learner noted "I had to concentrate and listened to my friend at all times to identify errors so that I could provide more feedback and help my friend to recognise and correct her own errors". They also reported the benefits of paying more attention to their friends' language production. One learner stated, "I became more adept at recognising and reflecting on my own and my friends' errors and seeking help to deal with these problems". As a result, they expressed "this [reflective] practice created more opportunities for thinking about language issues". They also remarked that error correction was fun at times. One learner commented "it was fun to point out my friend's errors while he was speaking, which made me feel cheerful and attentive".

Second, the learners reported that the reflective practice helped them establish a good social relationship during interaction. One learner stated "after the reflective practice, I felt free to seek for and provide help when requested by my partner without feeling embarrassed or disappointing my partner". Their good relationship was also shown in their appreciation of peer help: "I highly appreciated my partners' immediate help. I could receive immediate feedback from my partner rather than asking the teacher or spending time thinking about it, which is very good".

The learners also reported a collaborative mindset and showed collaborative dynamics after the reflective learning practice. One learner expressed "the reflective practice helped me know how 
to carry out collaborative conversations, and provide and receive more assistance in pair work, that's why I had more interaction and task contribution". Another learner explained "if one did not know what to say, the other would help with ideas. We do it frequently because we are encouraged to do so as we did in the previous part [the reflective learning practice session]'. Additionally, they reported that the collaborative mindset emphasised in the reflective learning practice enhanced their language production. One learner stated that "since I was encouraged to be collaborative and ask for help with language issues during the reflective practice activities, I felt more confident when speaking. I know that my language would not be judged by my partner for errors, so I felt I spoke a lot more". Another learner further commented "I needed to help my friend to speak a lot and I tried speaking more than before". In sum, the learners appeared to have formed a collaborative mindset prior to the interaction and established a good social relationship as reflected in their reported collaborative dynamics.

\section{Mediating factors}

The learners' responses also revealed factors mediating the impact of the reflective learning practice. The first factor is pertinent to the 'inert knowledge problem', referred to as a situation in which learners encounter difficulties applying what has been learnt into practice (Larsen-Freeman, 2003). For instance, one learner noted "I was aware of the need to pay attention to language issues, work collaboratively with friends, and provide help when necessary; however, I found it difficult executing these interactional strategies in subsequent interactions". Another learner stated "I learned a lot during the reflective practice activities, but it was not easy to apply all these strategies in all situations, so more practice will be useful to get used to using them".

The second factor was task features (i.e. task structure and topic). One learner explained "if the structure of task has a clear division of turn-taking such as story-retells, one talks and the other listens. There is not much room for interaction". Task topic and learners' characteristics were also reported to influence their interaction. One learner expressed "task topic was not suitable as in the 
case of the role-play tasks. Because we are young, it was difficult to play others' roles. It's better to use other topics related to our current lives".

Another mediating factor was learners' perceptions of their partners' performance. The learners reported issues with partners during interaction. One learner noted "it all depended on my partner. My partner did not speak much and she did not work very well as well. At times she did not really need my help". In another case, one learner stated "my partner did not understand what I needed and what I sought help for. This caused misunderstandings and pauses a lot". These results showed that learners' perceptions of their partners' performance affected how they applied what was learnt from the reflective learning practice.

Additionally, learners' perceptions of feedback provision appeared to be another mediating factor. One learner admitted "frequent identification of other's errors during interaction was good but not always easy to be carried out". Another learner explained "I was afraid of correcting my friend's errors, it was not very polite if the errors were minor". Furthermore, a learner whose errors were corrected repeatedly by his partner expressed "although error correction was good, I was a bit annoyed when frequently interrupted". Thus, some learners decided to not to provide feedback. One learner said "I did not dare to point out my friend's errors frequently, so I waited until the conversation ended and then told my partner about her errors, just major errors only". These responses showed that learners limited the provision of feedback to avoid conflicts during interaction.

Finally, proficiency was reported as an issue for offering and receiving feedback. One learner accepted that "it was not easy to identify my friend's errors. I could know some problems but not all. I even had problems with myself such as grammar, vocabulary and pronunciation, so I just focused on my issues without providing much help". Another learner complained "even though I explained, some grammatical structures were difficult, and not popular for others to know, so it was difficult to help". In some situations where learners reported to provide help frequently, they still 
expressed difficulties: "we tried but we did not understand each other when asking for help or correcting each other, so we moved on without focusing too much on errors".

\section{Discussion}

\section{Reflective learning practice and attention to form}

This study investigated the impact of reflective learning practice on learners' attention to form. The results showed that following the reflective learning practice, the learners appeared to self-correct their language errors more and engaged greater in metalinguistic talks. They also reported greater attention to partners' and their own language issues during interaction. This indicated that the reflective feature of the treatment (i.e. reflection on language produced by the learners themselves and partners) was effective in increasing learners' attention to form. The results support previous research findings that learners' attention to language features could be enhanced through consciously reflective and awareness-raising activities as focused in the treatment of this study (Fujii et al., 2016; Kim \& McDonough, 2011; Sato \& Lyster, 2012). Thus, the study suggested the reflective learning practice as one of the potentially effective awareness-raising and reflective activities for promoting learners' attention to form.

Regarding types of LREs, the results revealed that the reflective learning practice impacted positively on the occurrence of self-correction and metalinguistic talk. Because self-correction plays an important role in providing learners with opportunities to modify their language production and assisting them in restructuring their L2 knowledge, previous research has emphasized the necessity of promoting learners' self-correction to facilitate L2 learning (Shehadeh, 2001). This study, therefore, suggests that by asking learners to reflect continuously on their previous interactions, they were more likely to self-correct their language errors. Additionally, the greater occurrence of metalinguistic talk indicated that despite the focus of their interactions on meaning, the learners were likely to discuss more language issues that emerged incidentally in interaction after engaging 
in the reflective practice. This suggests that reflective learning practice could address the issue of low frequency of explicit talk about language form in peer interaction (Philp et al., 2010).

However, the results showed that there were no significant increases in the amount of othercorrection. This could be ascribed to learners' proficiency and perceptions of error correction. As reported earlier, some learners stated that it was not easy to identify their partners' errors due to their limited proficiency. This supports previous research findings that proficiency influenced the extent to which the learners attended to language forms (Authors, XXXX). In addition, some learners perceived frequent correction of their partners' errors as inappropriate and even unnecessary when those errors were minor. This suggested that individual and social factors (e.g. proficiency and perceptions of error correction) mediate the impact of the reflective learning practice on learners' attention to form.

\section{Collaborative mindset and collaboration in interaction}

The results that learners discussed language forms more frequently indicate that the reflective learning practice possibly aided the establishment of collaborative mindset among learners. Excerpt 3 in the Method section demonstrated that the learners appeared to be collaborative in discussing tense usage when re-telling a story. This collaboration suggests that they seemed comfortable discussing language issues explicitly. The learners' responses also support the interpretation that learners felt comfortable seeking and providing assistance. They reported that they were encouraged to do so when trained in the reflective learning activities. This could explain partly that the reflective learning activities were more likely to lead the learners to establish a collaborative mindset. Since a collaborative mindset could be conducive to a productive interaction that benefits the L2 learning (Sato, 2017b), the results suggest employing the reflective learning practice as one of the potential pedagogic procedures to expedite the establishment of learners' collaborative mindset which could result in learners' greater collaborative interaction.

\section{Factors mediating the effectiveness of reflective learning practice}


Individual, contextual and social factors were reported to mediate the effectiveness of the reflective learning practice. They included 'inert knowledge problem', task features, learners' characteristics, perceptions of partners' performance and feedback provisions, and proficiency. It is often assumed that pedagogical interventions that involve the explicit teaching of certain communication strategies would automatically lead learners to adopt and apply these strategies in subsequent performances. However, this study suggests a caution that learners may not apply the skills or knowledge in the intervention subsequently, which represents the so-called 'inert knowledge problem' (Larsen-Freeman, 2003). Although a majority of learners could apply what they learnt in the reflective learning practice, some reported that they had declarative knowledge based on the training they received, but could not transform it into the procedural knowledge (i.e. how to carry out them). One suggestion to address this issue, as one learner reported in the Result section, was that continuous practice could help apply what was learnt into subsequent performances.

Notably, the application of skills (e.g. providing feedback and using communication strategies) learnt explicitly in the reflective learning practice, could depend on learners' proficiency and perceptions of partner's performance. As reported earlier, learners expressed difficulties applying what they had learnt when their partners did not interact or perform well. Additionally, learners with limited proficiency seemed to be less able to identify partner's errors and provide help upon request, which contributed to less conversation. Previous research suggested that in order to provide feedback on partner's errors, the learners need to be confident in their proficiency (Philp et al., 2010). As admitted in their interview responses, some learners felt that they were not proficient enough to provide feedback on their partners' errors. This suggests that learners' proficiency needs to be taken into consideration when implementing reflective learning practice.

Furthermore, although instructed to provide feedback on partner's errors during interaction where possible, some learners reported not to do so frequently to avoid conflicts and preserve a 
good social relationship. This relates to Aston's (1986) caution that trouble-shooting in interaction may create 'less merry' atmosphere in task performance because there are cases where it may be better to 'let it pass' for the sake of efficiency and social relationship. This suggests that the learners at times prioritised and considered the social relationship an important aspect that needs to be maintained during interaction. Thus, it indicates that peer interaction is sensitive to the social relationship established by interlocutors during interaction and particularly learners' perceptions of maintaining this social relationship (Sato, 2017a).

Task-related factors such as task nature, structure, and topic also appeared to affect the occurrence of LREs, thereby mediating the impact of the reflective learning practice. Although the amount of metalinguistic talk in the reflective practice group increased significantly in the picturesequencing task, there was no significant increase in the amount of metalinguistic talk in the problem-solving task. The difference could be attributed to the nature of the task in which problemsolving task allows freer exchange of information without necessarily focusing on form (Nakahama, Tyler \& van Lier, 2001), whereas in picture-sequencing task, the learners might have needed to negotiate the forms (e.g. lexical forms in the pictures) in order to sequence the pictures.

Additionally, task structure (e.g. clear division of turn-taking in a story-retelling task) and unsuitable conversational roles (e.g. playing other's roles in a role-play task) were reported to affect how the learners interacted with each other. Taken together, the results support previous research findings that task factors play a role in shaping peer interaction. Thus, the effect of a pedagogical intervention on learner's attention to form during peer interaction, such as reflective learning practice, is subject to characteristics of the tasks.

\section{Limitations and implications}

The study has some limitations. First, despite providing evidence that the reflective learning practice enhanced learners' attention to form, this study has not established whether frequency of attention to form is linked to language learning, which warrants future research to address this gap. 
Second, although self-reported data could provide insights into individual and contextual factors mediating the impact of reflective learning practice, the results were exploratory, suggesting that experimental design studies are needed to tease apart the impact of these factors. Despite the limitations, the study offers some pedagogical implications. First, reflective learning practice could be used for promoting learners' attention to form and enabling them to monitor themselves during interaction. Second, the reflective learning practice, based on the reflective learning model, could be potentially effective for training learners to reflect on their interaction and language production for the sake of L2 learning. However, the teachers need to take into consideration individual, contextual and social factors, as observed in this study, as they affected the intervention's effectiveness. To conclude, this study suggests using reflective learning practice as a pedagogical tool to enhance learners' attention to form in order to maximise the benefits of peer interaction to L2 learning. 


\section{References}

Aston, G. (1986). Trouble-shooting in interaction with learners: the more the merrier? Applied Linguistics, 2, 128-143.

Barkhuizen, G. (2010). An extended positioning analysis of a pre-service teacher's better life small story. Applied Linguistics, 31, 282-300.

Brooks, L., \& Swain, M. (2009). Languaging in collaborative writing: Creation of and response to expertise. In A. Mackey \& C. Polio (Eds.), Multiple perspectives on interaction: Second language research in honour of Susan M. Gass (pp. 58-89). New York: Routledge.

Farrell, T. (2011). Exploring the professional role identities of experienced ESL teachers through reflective practice. System, 39, 54-62.

Fujii, A., Ziegler, N., \& Mackey, A. (2016). Peer interaction and metacognitive instruction in the EFL classroom. In Sato, M. \& Ballinger, S. (Eds.) Peer interaction and second language learning: Pedagogical potential and research agenda, (p.63 -90). Amsterdam: John Benjamins.

Kim, Y., \& McDonough, K. (2011). Using pretask modelling to encourage collaborative learning opportunities. Language Teaching Research, 14, 183-199.

Kim, Y., \& Tracy-Ventura, N. (2013). The role of task repetition in L2 performance development: What needs to be repeated during task-based interaction?, System, 41, 829-840.

Kolb, D. (1984). Experiential Learning as the Science of Learning and Development. Englewood Cliffs, NJ: Prentice Hall.

Kolb, D. (2014). Experiential learning: Experience as the source of learning and development. FT press.

Larsen-Freeman, D. (2003). Teaching language: From grammar to grammaring. Boston: Thomson/Heinle. 
Nakahama, Y., Tyler, A., \& van Lier, L. (2001). Negotiation of meaning in conversational and information gap activities: A comparative discourse analysis. TESOL Quarterly, 35, 377 405.

Pang, F., \& Skehan, P. (2014). Self-reported planning behaviour and second language performance in narrative retelling. In: P. Skehan (Ed.), Processing perspectives on task performance (pp. 95-127). Amsterdam: John Benjamins.

Philp, J., Adams, R., \& Iwashita, N. (2014). Peer interaction and second language learning. New York: Taylor \& Francis.

Philp, J., \& Mackey, A. (2010). Interaction research: What can socially informed approaches offer to cognitivists (and vice versa)? In R. Batstone (Ed.), Sociocognitive perspectives on language use and language learning (pp. 210-228). New York: Oxford University Press.

Philp, J., Walter, S., \& Basturkmen, H. (2010). Peer interaction in the foreign language classroom: what factors foster a focus on form?. Language Awareness, 19, 261-279.

Samuda, V. (2001). Guiding relationship between form and meaning during task performance: The role of the teacher. In: M. Bygate, P. Skehan, \& M. Swain (Eds.), Researching pedagogic tasks: Second language learning, teaching and testing. Harlow: Pearson Education.

Sato, M. (2017a). Oral corrective feedback: Multiple theoretical perspective. In Nassaji, H., \& Kartchava, E. (Eds.), Corrective feedback in second language teaching and learning: Research, theory, applications, implications (pp. 19-35). NY: Routledge.

Sato, M. (2017b). Interaction mindsets, interactional behaviors, and L2 development: An affectivesocial-cognitive model. Language Learning, 67, 249-283.

Sato, M. (2020). Metacognitive instruction for collaborative interaction: The process and product of self-regulated learning in the Chilean EFL context. In C. Lambert \& R. Oliver (Eds.), Using tasks in diverse contexts. Clevedon, UK: Multilingual Matters. 
Sato, M. \& Ballinger, S. (2016). Understanding peer interaction: Research synthesis and directions.

In M. Sato \& S. Ballinger (Eds.), Peer interaction and second language learning:

Pedagogical potential and research agenda (pp. 1-32). Amsterdam: John Benjamins.

Sato, M., \& Ballinger, S. (2012). Raising language awareness in peer interaction: a cross-context, cross-methodology examination. Language Awareness, 21, 157-179.

Sato, M. \& Loewen, S. (2018). Metacognitive instruction enhances the effectiveness of corrective feedback: Variable effects of feedback types and linguistic targets. Language Learning. Published online 20 February 2018.

Sato, M. \& Lyster, R. (2012). Peer interaction and corrective feedback for accuracy and fluency development. Studies in Second Language Acquisition, 34, 591-626.

Schon, D. (2016). The reflective practitioner: How professionals thin in action. New York: Routledge.

Shehadeh, A. (2001). Self-and other-initiated modified output during task-based interaction. TESOL Quarterly, 35, 433-457.

Skehan, P. (2016). Tasks versus conditions: Two perspectives on task research and their implications for pedagogy. Annual Review of Applied Linguistics, 36, 34-49.

Swain, M. (1998). Focus on form through conscious reflection. In: C. Doughty, \& J. Williams (Eds.), Focus on form in classroom second language acquisition (pp. 64-81). Cambridge: Cambridge University Press.

Swain, M., \& Lapkin, S. (1998). Interaction and second language learning: Two adolescent French immersion students working together. Modern Language Journal, 82, 320-337.

Teng, L. S., \& Zhang, L. J. (2016). A questionnaire-based validation of multidimensional models of self-regulated learning strategies. Modern Language Journal, 100, 674-701. 